\title{
Pain perception: predictive value of sex, depression, anxiety, somatosensory amplification, obesity, and age
}

This article was published in the following Dove Press journal:

Neuropsychiatric Disease and Treatment

I August 2016

Number of times this article has been viewed

\author{
Yuksel Kivrak' \\ Hatice Kose-Ozlece ${ }^{2}$ \\ Mehmet Fatih Ustundag ${ }^{3}$ \\ Mehmet Asoglu ${ }^{4}$ \\ 'Department of Psychiatry, \\ ${ }^{2}$ Department of Neurology, \\ Medical Faculty, Kafkas University, \\ Kars, ${ }^{3}$ Department of Psychiatry, \\ Medical Faculty, Ataturk University, \\ Erzurum, ${ }^{4}$ Department of Psychiatry, \\ Medical Faculty, Harran University, \\ Sanliurfa, Turkey
}

Objective: Factors affecting pain sensation are still being investigated. In this study, we aimed to examine the effects of sex, age, body mass index (BMI), somatosensory amplification, anxiety, and depression on the perception of pain.

Methods: Venipuncture was performed on 140 healthy individuals. All the cases completed a sociodemographic data form, visual analog scale (VAS), Beck Anxiety Inventory (BAI), Beck Depression Inventory, and Somatosensory Amplification Scale. Height and weight were also measured.

Results: When both the sexes were compared, there was no difference in terms of VAS, BMI, age, and Beck Depression Inventory, but Somatosensory Amplification Scale and BAI were found to be higher in females. A correlation was found among VAS points, BAI, and BMI. The results of a regression analysis show that the BAI score is a predictor for the VAS score.

Conclusion: These results indicate that anxiety may be a predictor of pain, whereas sex, depression, somatosensory amplification, age, and weight do not appear to influence the perception of pain.

Keywords: pain perception, anxiety, depression, obesity

\section{Introduction}

The word "pain" is derived from an ancient Greek word "poine" (penalty). ${ }^{1}$ Aristotle described pain as suffering of the soul. ${ }^{2}$ The words "pain", "hurt", and "suffering" may be used to express both bodily and mental discomforts. ${ }^{3}$ According to the International Association for the Study of Pain, pain is "an unpleasant sensory and emotional experience associated with actual or potential tissue damage, or described in terms of such damage". ${ }^{4}$ It is a complaint related to the interaction of an individual's physical, psychological, and social situations. It indicates the disruption of biopsychosocial balance. $^{1}$

Approximately half of the patients referred for examination have a pain complaint of some sort. There are inflammatory and neuropathic processes related to physiological tissue destruction in acute pain. ${ }^{5}$ This is accompanied by an increased sympathetic and noradrenergic activity and a reduction in parasympathetic activity. ${ }^{6}$ Generally, an anxiety reaction develops due to acute pain. ${ }^{1}$ Depression and anxiety top the list of psychiatric disorders that frequently affect both male and female. ${ }^{7}$ Just as pain can cause psychiatric disorders, psychiatric diseases may affect the experience of pain. When analyzing the combination of physical pain and psychiatric disorders, a causeeffect relationship cannot be determined generally. ${ }^{8}$ Although there are studies on
Correspondence: Hatice Kose-Ozlece Department of Neurology, Medical Faculty, Kafkas University, Inonu Street, Pasacayiri Avenue, Kars, 36000 Turkey Tel +905072336968

Fax +90474225 II

Email haticekse@hotmail.com 
this topic, the majority state that "more studies on this topic would be beneficial" $", 10$. Research related to the effect of sex differences on pain perception are continually increasing, and recently, there is an increase in the number of studies on this topic. Compared with the 1990s, the number of publications on this topic has been increased by $2,000 \% .{ }^{9} \mathrm{~A}$ review paper published recently emphasized that a variety of biopsychosocial circumstances may affect the pain perception of male and female, which thus necessitates further research on this topic. ${ }^{10}$

The majority of experimental studies related to pain caused by tissue damage have used animal models. Studies on humans have mostly included individuals with pain complaints. To our knowledge, there is no study on humans assessing the effects of depression, anxiety, sex, somatosensory amplification, age, and weight on pain perception due to tissue damage.

Laboratory diagnostics is a pivotal part of clinical decision making so that venipuncture is one of the most commonly conducted invasive procedures. ${ }^{11}$ In this study, we aimed to determine whether there was a relationship between the perception of pain from venipuncture and sex and whether this relationship was affected by depression, anxiety, somatosensory amplification, age, and weight.

\section{Materials and methods}

This study was conducted with individuals approaching Kafkas University Hospital for a routine checkup. The study was completed in a case-controlled manner, and Kafkas University Local Ethical Committee approval and written informed consent were obtained. Also, the guidelines in the Declaration of Helsinki (2004) were followed.

Before beginning the study, a set of tests was prepared. A preliminary study was completed with ten male and ten female requesting examination. The visual analog scale (VAS) was found to be $4 \pm 2$. For a difference of $0.5, \alpha=0.01$, power $=0.9$, and the minimum sample size was calculated as 137. Patients using psychotropic medications; those with dementia, cognitive disorders, and acute or chronic diseases in their medical history; and those under the age of 16 years were excluded from the study. Considering the possibility of lack of completion, the target was set at 160 individuals. Patients were randomly chosen from those applying to the laboratory for health checkups with a random number table on random days. Interviews were conducted with 160 volunteers who agreed to participate in the study. As 17 people did not fully complete the tests and three people had phobias (blood and needles), they were excluded from the study. Thus, the study was completed with 140 people.
Information about the study was given to those who agreed to participate. Height and weight were measured. Weight was divided by the square of height to determine the body mass index (BMI). Study subjects were taken to a room where they could be alone. Tests including the sociodemographic data form, Beck Anxiety Inventory (BAI), Beck Depression Inventory (BDI), and Somatosensory Amplification Scale (SAS) were completed before venipuncture, and the VAS was completed after venipuncture.

\section{Tools: inventories and psychometric tests}

Sociodemographic Data Collection Form was prepared by the researcher.

\section{Visual analog scale}

The VAS is used to assess the severity of a patient's pain. It is $10 \mathrm{~cm}$ long with $0=$ no pain, written at one end, and $10=$ most severe pain, written at the other. Patients are asked to mark where along the scale they would place the pain they perceived. The distance is measured in centimeters. The value shows the severity of pain perceived by the patient. ${ }^{12}$

\section{Beck Anxiety Inventory}

The BAI was developed by Beck et $\mathrm{al}^{13}$ to measure the anxiety experienced by an individual. It is a Likert-type scale filled in by the individuals. The points vary between 0 and 63 . For each item, one of the choices of none, slightly, moderately, and severely is marked. The validity and reliability have been completed by the Tukey's test. ${ }^{14}$

\section{Beck Depression Inventory}

The BDI inventory was developed by Beck et al ${ }^{15}$ to measure a variety of symptoms of depression. It is a 21 -item checklist that the patients fill in themselves. They select the most appropriate of the four choices. The validity and reliability have been completed by the Tukey's test. ${ }^{16}$

\section{Somatosensory Amplification Scale}

The SAS is filled in by patients to investigate their somatosensory amplification with ten items with points between 1 and 5 . With validity and reliability tested for Turkish healthy and patient groups, ${ }^{17}$ the scale was developed by Barsky et al ${ }^{18}$ to study the normal somatic senses of a person.

\section{Statistical assessment of data}

To evaluate the data, the Statistical Package for Social Sciences (SPSS, version 2.0; SPSS Inc., Chicago, IL, USA) program was used. Each group was tested with Kolmogorov-Smirnov 
test to investigate the normal distribution of the obtained data. The data with normal distribution were analyzed with the Student's $t$-test, while Mann-Whitney $U$-test was used for data without normal distribution. Correlation analysis was completed with the Pearson's and Spearman's methods. Chi-square test was used to analyze the quantitative data while those with expected value $<5$ were analyzed with Fischer's exact chi-square test. To find the predictive values for pain scores, the linear regression analysis method was used. The data obtained were presented as arithmetic mean \pm standard deviation, while quantitative data were presented as number $\%$. The level of significance was determined as $P<0.05$.

\section{Results}

The study group consisted of $42.1 \%$ male $(n=59)$ and $57.9 \%$ female $(n=81)$ participants. The average age of the female was $40.2 \pm 17.4$ years, while the average age of the male was $40.9 \pm 14.4$ years $(P=0.79)$. Sixty-one female were married $(75.3 \%)$, while 20 were not $(24.7 \%)$. Thirty-six male were married (61\%) and 23 were not (39\%). There was no difference between the groups in terms of marital status. When economic circumstances were examined, there were seven (8.6\%), 15 (18.5\%), 36 (44.4\%), and 23 (28.4\%) female and five (8.5\%), $14(23.7 \%), 29(49.2 \%)$, and eleven (18.6\%) male in the worst-, second-worst-, second-best-, and best-income groups, respectively. The difference between the groups was not significant. The average height $(1.72 \pm 0.065 \mathrm{~m})$ and weight $(75.84 \pm 10.7 \mathrm{~kg})$ of male was greater than those of female $(1.62 \pm 0.059 \mathrm{~m} ; 65.11 \pm 0.065 \mathrm{~kg})$, but there was no significant difference between them in terms of BMI $\left(24.68 \pm 4.1 \mathrm{~kg} / \mathrm{m}^{2}\right.$ vs $\left.25.31 \pm 3.04 \mathrm{~kg} / \mathrm{m}^{2}\right)$. In terms of SAS, the points for female were $24.68 \pm 6.3$, which was greater than the points for male $(21.67 \pm 5 ; F=1.41, P=0.004)$. In terms of anxiety points, there was a significant difference with respect to sex (female 20.48 \pm 9.87 , male $14.46 \pm 8.80, F=1.187$, $P=0.002)$. The depression points for female $(4.96 \pm 7.27)$ were more than those for male (4.32 \pm 5.44$)$, but the difference was not significant $(F=2.610, P=0.57$; Table 1$)$. There was a correlation between VAS and BMI $(r=-1.79, P=0.034)$ and BAI $(r=0.250, P=0.003)$ points (Table 2$)$.

Using the VAS scores as dependent variables and using BAI, BDI, SAS, BMI, and sex as independent variables, the regression model found that BAI was a predictive variable for VAS scores $\left(R=0.298, R^{2}=0.089\right.$, adjusted $R^{2}=0.055$; Table 3).

\section{Discussion}

In our study, we aimed to examine the effects of sex, depression, anxiety, somatosensory amplification, age, and weight on the perception of pain. We found no difference in the perception of pain between the sexes, but the anxiety and somatosensory amplification scores for female were higher than those for male. Anxiety score was a predictor for pain perception. It was found that depression, BMI, and somatosensory amplification were not the predictors of pain perception.

Table I Sociodemographic features of the groups

\begin{tabular}{|c|c|c|c|c|c|c|}
\hline \multirow[t]{2}{*}{ Sociodemographic features } & \multirow{2}{*}{\multicolumn{2}{|c|}{$\begin{array}{l}\text { Female }(n=8 I) \\
\text { Mean } \pm \text { SD }\end{array}$}} & \multirow{2}{*}{\multicolumn{2}{|c|}{$\begin{array}{l}\text { Male }(n=59) \\
\text { Mean } \pm \text { SD }\end{array}$}} & \multirow[t]{2}{*}{$t$} & \multirow[t]{2}{*}{$P$} \\
\hline & & & & & & \\
\hline Age, years & \multicolumn{2}{|c|}{$40.2 \pm 17.4$} & \multicolumn{2}{|c|}{$40.93 \pm 14.43$} & 0.768 & 0.795 \\
\hline Education, years & \multicolumn{2}{|c|}{$6.45 \pm 4.05$} & \multicolumn{2}{|c|}{$8.14 \pm 3.04$} & 13.649 & 0.009 \\
\hline Height, m & \multicolumn{2}{|c|}{$1.62 \pm 0.0599$} & \multicolumn{2}{|c|}{$1.72 \pm 0.0653$} & 0.216 & 0.000 \\
\hline Weight, kg & \multicolumn{2}{|c|}{$65.11 \pm 10.64$} & \multicolumn{2}{|c|}{$75.84 \pm 10.7$} & 0.047 & 0.000 \\
\hline BMI, kg/m² & \multicolumn{2}{|c|}{$24.68 \pm 4.10$} & \multicolumn{2}{|c|}{$25.31 \pm 3.04$} & 9.066 & 0.32 \\
\hline VAS & \multicolumn{2}{|c|}{$4.28 \pm 2.05$} & \multicolumn{2}{|c|}{$3.76 \pm 1.95$} & 0.768 & 0.133 \\
\hline SAS & \multicolumn{2}{|c|}{$24.65 \pm 6.30$} & \multicolumn{2}{|c|}{$21.68 \pm 5.32$} & 1.41 & 0.004 \\
\hline $\mathrm{BAI}$ & \multicolumn{2}{|c|}{$20.48 \pm 9.87$} & \multicolumn{2}{|c|}{$14.46 \pm 8.80$} & 1.187 & 0.002 \\
\hline BDI & \multicolumn{2}{|c|}{$4.96 \pm 7.27$} & \multicolumn{2}{|c|}{$4.32 \pm 5.44$} & 2.610 & 0.57 \\
\hline Marital status & $\mathbf{n}$ & $\%$ & $\mathbf{n}$ & $\%$ & $\chi^{2}$ & $P$ \\
\hline Married & 61 & 62.9 & 36 & 37.1 & 3.27 & 0.070 \\
\hline Unmarried & 23 & 53.5 & 20 & 46.5 & & \\
\hline \multicolumn{7}{|l|}{ Economic circumstances (USD) } \\
\hline$\$ 0-125$ & 7 & 58.3 & 5 & 41.7 & 1.94 & 0.5 \\
\hline$\$ 125-375$ & 15 & 51.7 & 14 & 48.3 & & \\
\hline$\$ 375-750$ & 36 & 55.4 & 29 & 44.6 & & \\
\hline$\$ 750-2,500$ & 23 & 67.6 & II & 32.4 & & \\
\hline
\end{tabular}

Abbreviations: BAI, Beck Anxiety Inventory; BDI, Beck Depression Inventory; BMI, body mass index; P, P-value (two-tailed); SAS, Somatosensory Amplification Scale; $\mathrm{SD}$, standard deviation; $t$, paired $t$-test; VAS, visual analog scale. 
Table 2 VAS correlations

\begin{tabular}{|c|c|c|c|c|c|c|c|c|c|c|}
\hline & \multicolumn{2}{|l|}{ Age } & \multicolumn{2}{|l|}{ SAS } & \multicolumn{2}{|l|}{ BAI } & \multicolumn{2}{|l|}{ BDI } & \multicolumn{2}{|l|}{ BMI } \\
\hline & $r$ & $P$ & $r$ & $P$ & $r$ & $P$ & $r$ & $P$ & $r$ & $P$ \\
\hline VAS & -0.090 & 0.290 & 0.082 & 0.331 & 0.250 & 0.003 & 0.013 & 0.875 & -1.79 & 0.034 \\
\hline
\end{tabular}

Note: Results are in response to Pearson's and Spearman's tests.

Abbreviations: BAI, Beck Anxiety Inventory; BDI, Beck Depression Inventory; BMI, body mass index; P, P-value (two-tailed); SAS, Somatosensory Amplification Scale; VAS, visual analog scale.

Although no difference was found between male and female in terms of pain perception in our study, in the literature, many studies report a difference, as well as there are studies that report that no differences exist. ${ }^{10,19-22}$ One reason that a difference did not appear in our study may be due to the method used. In a review of 172 articles researching the perception of experimentally induced cold, heat, pressure, ischemic, muscle, chemical, and visceral pain, the pain threshold for pressure was lower in female than in male, but the pain thresholds for cold and ischemic pain were reported to be comparable. ${ }^{23}$ When examined in terms of pain tolerance, the tolerance of both the sexes to ischemic pain was comparable, female had lower tolerance to heat, cold, and pressure than male. ${ }^{24}$ Another reason for the contradictory publications may be the time factor. Morin et $\mathrm{al}^{24}$ in a study of patients after surgery found that pain increased at night in male and during the day in female. When examined in terms of not just superficial but also visceral pain, the difference between the sexes is controversial. Some studies show that there may be differences. ${ }^{25-27}$ For example, Nguyen et $\mathrm{a}^{25}$ in a study of esophageal distension found that the pain threshold of female was lower. In some studies assessing people who underwent a variety of operations, the pain during recovery was greater in female. ${ }^{26,27}$ However, Sloots et $\mathrm{al}^{28}$ in a study researching the rectal stimulation found that there was no difference in terms of sex or age. If sex is considered as an important factor in terms of pain perception, it is expected that there would be a difference between the sexes in terms of disability caused by pain, but in a study on this topic found no differences in pain-induced disabilities between male and female. ${ }^{29}$

Table 3 Linear regression model when VAS is not dependent

\begin{tabular}{clllll}
\hline Model & B & $\begin{array}{l}\text { Standard } \\
\text { error }\end{array}$ & Beta & $\boldsymbol{t}$ & $\boldsymbol{P}$ \\
\hline Constant & 4.81 & 1.48 & & 3.25 & 0.001 \\
SAS & 0.01 & 0.03 & 0.003 & 0.28 & 0.98 \\
BAI & 0.047 & 0.019 & 0.225 & 2.505 & 0.013 \\
BDI & -0.015 & 0.027 & -0.048 & -0.542 & 0.589 \\
Sex & 0.245 & 0.355 & 0.06 & 0.691 & 0.491 \\
BMI & -0.078 & 0.046 & -0.142 & -1.693 & 0.093 \\
\hline
\end{tabular}

Abbreviations: BAl, Beck Anxiety Inventory; BDI, Beck Depression Inventory; BMI, body mass index; P, P-value (two-tailed); SAS, Somatosensory Amplification Scale; $t$, paired $t$-test; VAS, visual analog scale.
The complete correlation analysis found a significant correlation between VAS and BAI. Our result is in accordance with the literature. Many studies show that negative emotions increase the pain. ${ }^{9,30,31}$ It has been known for many years from experimental pain studies that the state of anxiety increases the sensitivity to experimental pain. ${ }^{32}$ Not only in experimental studies but also in reality, anxiety before the medical procedures in both children and adults increases the pain after the procedure. ${ }^{33}$ As expected, reducing anxiety with medication reduces the perception of pain. While experiencing the pain, emotional stimulation is important and emotional changes affect pain tolerance. ${ }^{34}$ It has been shown that anxiety increases hyperalgesia. ${ }^{32,34}$ Surprisingly, although female's anxiety levels were higher than male, we found no difference in VAS values with respect to sex. This may explain the question of whether the effect of anxiety on pain changes with respect to sex. Thus, although female's anxiety levels were higher, in male anxiety may cause an increase in pain. ${ }^{35,36}$

In our study, we did not find a correlation between depression points and VAS points. The relationship between depression and pain has not been fully explained. A research study indicates that depression may lead to an increase in comorbid pain. ${ }^{37}$ One of the reasons for this is that depression may increase the sensitivity to experimental pain. The relationship between depression and an individual's pain threshold is controversial. In addition to articles reporting that depression increases the pain threshold, there are publications reporting no differences or an education in pain threshold. ${ }^{38,39}$ The reason for the differences in the literature may be that comorbid anxiety has not been sufficiently assessed or that there are differences in pain receptors.

In this study, we did not find a correlation between VAS and age. Although many studies worked on the relationship between age and pain, this topic has not been fully explained. ${ }^{40-44}$ Pickering et al ${ }^{40}$ found that pressuresensitive nociception decreased with age in male. Some studies have shown a relationship between age and pain threshold, ${ }^{41,42}$ whereas many other studies have proposed that there is no relationship. ${ }^{43,44}$ The reason for these 
differences may be the differences in methods used to gather data, cultural differences of subjects, and no assessments of concurrent anxiety.

We found a negative correlation between VAS and BMI because of a rise in pain threshold caused by increased BMI. Studies on both humans and mice have found that obesity is related to an increase in pain threshold. ${ }^{45-47}$ In our study, in addition to the correlation between BMI and VAS score, we found that according to linear regression analysis, BMI was not a predictor of the severity of pain. The strong points of our study is that it is the first study on one of the most frequently performed invasive interventions, intravenous blood sampling; that subjects were chosen at random; that the scales and inventories used had validity and reliability studies completed for the Turkish translations; and that subjects had no disorders that may induce or affect pain. As the correlations between pain and age, BMI, somatosensory amplification, anxiety, and depression were examined in addition to sex, we believe that this study is important. The study contributes to the research on sex and pain. While female had more amplification of somatic senses and are more anxious, their pain assessment was the same as male. Further research on this topic would be beneficial.

\section{Limitations}

There are some limitations to our study. The first is that the study was completed in a university hospital and the tests used were all self-reported. The second limitation is that our study used only a single type of needle. However, we do not consider this limitation significant because Yee et $\mathrm{a}^{48}$ found no difference while comparing pain from $23 \mathrm{G}$ and $25 \mathrm{G}$ needles. Another limitation is that we evaluated pain only during intravenous intervention. It is not known whether the research findings will be valid for pain perception from other pain receptors. Another limitation preventing the generalization of our results is that we did not include children, the elderly, or hospitalized or sick patients. Research on these topics would be beneficial.

\section{Conclusion}

These results indicate that anxiety may be a predictor of pain, whereas sex, depression, somatosensory amplification, age, and weight do not appear to influence the perception of pain.

Precautions to reduce anxiety may also reduce the pain felt by the person. Health personnel should be aware of this, and it may be useful to emphasize the importance of anxiety for pain perception during the training of health personnel. The clinician paying attention to this situation may positively contribute to the patient-doctor relationship and increase compliance with treatment.

\section{Author contributions}

YK designed the study and collected the data. HKO drafted the article and revised it critically for important intellectual content. MFU collected data and made the final approval of the version to be published. All authors contributed toward data analysis, drafting and revising the paper and agree to be accountable for all aspects of the work.

\section{Disclosure}

The authors report no conflicts of interest in this work.

\section{References}

1. Kara H, Abay E. Kronik ağrıya psikiyatrik yaklaşım [Psychiatric Approachs to Chronic Pain Patients]. Anadolu Psikiyatri Derg. 2000;1(2):89-99. Turkish.

2. Kaplan HI, Sadock BJ, editors. Chronic pain. In: Comprehensive Textbook of Psychiatry. Vols 1 and 2 [Internet]. Baltimore: Williams \& Wilkins Co; 1989:1264-1272.

3. Fogel BS, Schiffer RB, Rao SM, editors. Pain and psychopathology. In: Neuropsychiatry. Williams \& Wilkins; (Philadelphia) 1996.

4. Merskey H, Bogduk N, editors. Classification of chronic pain: descriptions of chronic pain syndromes and definition of pain terms. In: Task Force on Taxonomy of the International Association for the Study of Pain. Seattle: IASP; 1994.

5. Quadros AU, Cunha TM. C5a and pain development: an old molecule, a new target. Pharmacol Res. Epub 2016 Feb 11.

6. Kobuch S, Fazalbhoy A, Brown R, Macefield VG. Inter-individual responses to experimental muscle pain: baseline physiological parameters do not determine whether muscle sympathetic nerve activity increases or decreases during pain. Front Neurosci. 2015;9:471.

7. Kıvrak Y, Ülker K, Gündüz S, Ari M. Electroconvulsive therapy during pregnancy. Kafkas J Med Sci. 2011;1(3):133-138.

8. Tütüncü R, Günay H. Chronic pain, psychological factors and depression. J Dicle Med. 2011;38(2):257-262.

9. Fillingim RB, King CD, Ribeiro-Dasilva MC, Rahim-Williams B, Riley JL III. Sex, gender, and pain: a review of recent clinical and experimental findings. Pain. 2009;10(5):447-485.

10. Racine M, Tousignant-Laflamme Y, Kloda LA, et al. A systematic literature review of 10 years of research on sex/gender and pain perception - part 2: do biopsychosocial factors alter pain sensitivity differently in women and men? Pain. 2012;153(3):619-635.

11. Lippi G, Blanckaert N, Bonini P, et al. Causes, consequences, detection, and prevention of identification errors in laboratory diagnostics. Clin Chem Lab Med. 2009;47(2):143-153.

12. Price DD, McGrath PA, Rafii A, Buckingham B. The validation of visual analogue scales as ratio scale measures for chronic and experimental pain. Pain. 1983;17(1):45-56.

13. Beck AT, Epstein N, Brown G, Steer RA. An inventory for measuring clinical anxiety: psychometric properties. J Consult Clin Psychol. 1988;56(6):893.

14. Ulusoy M, Sahin NH, Erkmen H. Turkish version of the Beck Anxiety Inventory: psychometric properties. J Cogn Psychother. 1998; $12: 163-172$.

15. Beck AT, Ward CH, Mendelson M, Mock J, Erbaugh J. An inventory for measuring depression. Arch Gen Psychiatry. 1961;4(6):561-571.

16. Hisli N. Beck Depresyon Ölçeği'nin bir Türk örnekleminde geçerlilik ve güvenilirliği. [The reliability and validity of Becks Depression Inventory in a Turkish population]. Turk J Psychol. 1988;6:118-122. Turkish. 
17. Güleç H, Sayar K, Güleç MY. The reliability and validity of the Turkish form of the somatosensory amplification scale. Düşünen Adam Psikiyatri Nöroloji Bilim Derg. 2007;20(1):16-24.

18. Barsky AJ, Goodson JD, Lane RS, Cleary PD. The amplification of somatic symptoms. Psychosom Med. 1988;50(5):510-519.

19. Hashmi JA, Davis KD. Deconstructing sex differences in pain sensitivity. Pain. 2014;155(1):10-13.

20. Gautschi OP, Corniola MV, Smoll NR, et al. Sex differences in subjective and objective measures of pain, functional impairment, and health-related quality of life in patients with lumbar degenerative disc disease. Pain. 2016;157(5):1065-1071.

21. Gonzalez-Liencres C, Breidenstein A, Wolf OT, Brüne M. Sexdependent effects of stress on brain correlates to empathy for pain. Int J Psychophysiol. 2016;S0167-8760(16)30055-1.

22. Nahman-Averbuch H, Dayan L, Sprecher E, et al. Sex differences in the relationships between parasympathetic activity and pain modulation. Physiol Behav. 2016;154:40-48.

23. Racine M, Tousignant-Laflamme Y, Kloda LA, Dion D, Dupuis G, Choinière M. A systematic literature review of 10 years of research on sex/gender and experimental pain perception - part 1: are there really differences between women and men? Pain. 2012;153(3):602-618.

24. Morin C, Lund JP, Villarroel T, Clokie CML, Feine JS. Differences between the sexes in post-surgical pain. Pain. 2000;85(1):79-85.

25. Nguyen P, Lee SD, Castell DO. Evidence of gender differences in esophageal pain threshold. Am J Gastroenterol. 1995;90(6):901.

26. Aubrun F, Salvi N, Coriat P, Riou B. Sex-and age-related differences in morphine requirements for postoperative pain relief. Anesthesiology. 2005;103(1):156

27. Krogstad BS, Jokstad A, Dahl BL, Vassend O. The reporting of pain, somatic complaints, and anxiety in a group of patients with TMD before and 2 years after treatment: sex differences. J Orofac Pain. 1996; 10(3):263-269.

28. Sloots CEJ, Felt-Bersma RJF, Cuesta MA, et al. Rectal visceral sensitivity in healthy volunteers: influences of gender, age and methods. Neurogastroenterol Motil. 2000;12(4):361.

29. Keogh E, McCracken LM, Eccleston C. Gender moderates the association between depression and disability in chronic pain patients. Eur J Pain. 2006;10(5):413-413.

30. Petrini L, Matthiesen ST, Arendt-Nielsen L. The effect of age and gender on pressure pain thresholds and suprathreshold stimuli. Perception. 2015;44(5):587-596.

31. Baker N.Using Cognitive Behavior Therapy and Mindfulness Techniques in the Management of Chronic Pain in Primary Care. Prim Care. 2016;43(2):203-216.

32. Rhudy JL, Meagher MW. Fear and anxiety: divergent effects on human pain thresholds. Pain. 2000;84(1):65-75.
33. Palermo TM, Drotar D. Prediction of children's postoperative pain: the role of presurgical expectations and anticipatory emotions. J Pediatr Psychol. 1996;21(5):683-698.

34. Chapman CR, Feather BW. Effects of diazepam on human pain tolerance and pain sensitivity. Psychosom Med. 1973;35(4):330-340.

35. Jones A, Zachariae R, Arendt-Nielsen L. Dispositional anxiety and the experience of pain: gender-specific effects. Eur J Pain. 2003;7(5): 387-395.

36. Hirsh AT, Waxenberg LB, Atchison JW, Gremillion HA, Robinson ME. Evidence for sex differences in the relationships of pain, mood, and disability. Pain. 2006;7(8):592-601.

37. Radat F, Koleck M. Pain and depression: cognitive and behavioural mediators of a frequent association. Encephale. 2011;37(3):172-179.

38. Dickens C, McGowan L, Dale S. Impact of depression on experimental pain perception: a systematic review of the literature with meta-analysis. Psychosom Med. 2003;65(3):369-375.

39. Ward NG, Bloom VL, Dworkin S, Fawcett J, Narasimhachari N, Friedel RO. Psychobiological markers in coexisting pain and depression: toward a unified theory. J Clin Psychiatry. 1982;43(8 Pt 2): 32-41.

40. Pickering G, Jourdan D, Eschalier A, Dubray C. Impact of age, gender and cognitive functioning on pain perception. Gerontology. 2002; 48(2):112-118.

41. Wandner LD, Scipio CD, Hirsh AT, Torres CA, Robinson ME. The perception of pain in others: how gender, race, and age influence pain expectations. J Pain. 2012;13(3):220-227.

42. Rittger H, Rieber J, Breithardt OA, et al. Influence of age on pain perception in acute myocardial ischemia: a possible cause for delayed treatment in elderly patients. Int J Cardiol. 2011;149(1):63-67.

43. Gibson SJ, Farrell M. A review of age differences in the neurophysiology of nociception and the perceptual experience of pain. Clin J Pain. 2004;20(4):227-239.

44. Yezierski RP. The effects of age on pain sensitivity: preclinical studies. Pain Med. 2012;13(Supp1 2):S27-S36.

45. Ramzan I, Wong BK, Corcoran GB. Pain sensitivity in dietary-induced obese rats. Physiol Behav. 1993;54(3):433-435.

46. Khimich S. Level of sensitivity of pain in patients with obesity. Acta Chir Hung. 1997;36(1-4):166-167.

47. Maffiuletti NA, Morelli A, Martin A, et al. Effect of gender and obesity on electrical current thresholds. Muscle Nerve. 2011;44(2):202-207.

48. Yee K, Shetty AL, Lai K. ABG needle study: a randomised control study comparing $23 \mathrm{G}$ versus $25 \mathrm{G}$ needle success and pain scores. Emerg Med J. 2014;(5):343-347.
Neuropsychiatric Disease and Treatment

\section{Publish your work in this journal}

Neuropsychiatric Disease and Treatment is an international, peerreviewed journal of clinical therapeutics and pharmacology focusing on concise rapid reporting of clinical or pre-clinical studies on a range of neuropsychiatric and neurological disorders. This journal is indexed on PubMed Central, the 'PsycINFO' database and CAS,
Dovepress

and is the official journal of The International Neuropsychiatric Association (INA). The manuscript management system is completely online and includes a very quick and fair peer-review system, which is all easy to use. Visit http://www.dovepress.com/testimonials.php to read real quotes from published authors. 